\title{
Family Sociology
}

National Cancer Institute

\section{Source}

National Cancer Institute. Family Sociology. NCI Thesaurus. Code C18791.

The study of individual and group behavior with respect to family interactions. 